\title{
On Source Language Interference in Interpretation
}

\author{
Haiyan Gao \\ School of Foreign Languages, He Ze City, China
}

\begin{abstract}
Source Language interference (SLI), or cross-linguistic influence, is the result of language transfer and interpretation. Language transfer can be classified into positive transfer and negative transfer or interference. While positive transfer facilitates the communicative function of interpretation, negative transfer may have negative impact, weakening the content and form of interpretation, which will influence the realization of its communicative function. In the thesis, concept and features of interpretation, as well as its relationship with language interference are explored. Then some interpreting materials are analyzed to prove the influence of SLI in interpretation. Finally, some general approaches and specific strategies are put forward, aiming at avoiding the SLI as much as possible and improving the quality of interpretation.
\end{abstract}

Index Terms - source language interference, interpretation, approaches \& strategies

\section{INTRODUCTION}

Interpreting is a special cross-linguistic activity with the interpreter involved as the bilingual or multilingual. The interpreter is first and foremost a bilingual who can speak both SL and TL. It is more often the case that the SL and TL are not acquired at the same time. Then there exists the possibility of language transfer, or cross-linguistic influence, between SL and TL. In the broad sense, language transfer is any kind of movement and/or influence of concepts, knowledge, skills or linguistic elements (structures, forms), in either direction, between L1 (the first language) and the subsequent language(s). Language transfer is not simply interference. It includes both positive transfer and negative transfer.

In the study of interpretation, it is found that much of the influence of the native language (or some other previously learned language) can be very helpful, especially when the differences between two languages are relatively few. Positive transfer refers to the facilitating influence of cognate vocabulary or any other similarities between the native and target languages (Daniel, 1995). However, negative transfer, or Source Language Interference (SLI), is the prime concern this thesis and will be elaborated in the following.

To prove the influence of SLI in interpretation, the lecture materials of Premier Wen Jiabao during the Two Session/Meetings are analyzed. Finally some relevant approaches and strategies are put forward specifically to minimize SLI and improve the quality of interpretation. General approaches are the basic methodologies that should be born in the interpreter's mind throughout the interpretation process, including awareness of language difference, general correspondence, and interpretive approach. Specific strategies are the particular techniques to tackle the source text, which are chosen by the interpreter consciously or subconsciously. In this thesis, three strategies are proposed to curb SLI including linearity, anticipation and the principle of economy.

\section{LITERATURE REVIEW}

\section{A. Analysis of Interpretation}

It is necessary to introduce interpretation and its features here in that it provides some basic information where SLI arises and serves as a basis for further discussion.

\section{Definition of interpretation}

According to Holly, In interpretation the interpreter is isolated in a booth. He speaks at the same time as the speaker and therefore has no need to memorize or jot down what is said. Moreover, the process of analysis-comprehension and of reconstruction-expression is telescoped. In this thesis interpretation is defined as a process of transferring in oral form what is expressed in another language by the speaker at approximately the same time as him/her (obin, 1993).

\section{Features of interpretation}

Owing to the special working process of interpretation, there are many features associated with it.

Interpreters work under tremendous pressure, temporal pressure constituting an important part. As the definition indicates, the interpreter speaks at the same time with the speaker, so one requirement is that s/he must adopt the rhythm of the speaker.

Production difficulty may also be brought forward by the same cause. In those cases, the EVS (ear-voice-span) will be lengthened. The interpreter, however, must not allow any delay in the process resulting in his/her losing track of the SL rhythm or overload of short-term memory, which may mean overall failure. 
Interpretation varies with different language pairs, which are referred to as language specificity. In other words, interpretation between some language pairs is easier than otherwise. Although it has not been demonstrated systematically, there are facts and strong arguments for it. For example, it is significant that many interpreters with Chinese, whether A or B, almost prefer working into rather than from Chinese, whatever the type of discourse. Language specificity is closely related with SLI.

\section{B. Source Language Interference (SLI) and Interpretation}

In this part the causes of SLI will be analyzed in terms of structural and non-structural aspects. Then its consequence on interpretation is analyzed in terms of content and form.

\section{Causes of Source Language Interference (SLI)}

It is assumed that the learner who comes in contact with a foreign language may resort to his/her native language features to replace those difficulties in the target language. In that case, negative transfer occurs. In this thesis, negative transfer, or interference, refers to the influence resulting from dissimilarities of the SL and the TL which has deteriorating impact on interpretation.

Another point that needs to be clarified is that language interference takes place in dual directions, i.e., not only from native language to a second or third language but also vice versa. In particular, this paper deals with the language interference, between English and Chinese, which are two languages with great disparity, under the specific situation of interpretation. In interpretation, the influence arises mainly from the SL, no matter Chinese or English, since the interpreter extracts the message from the SL and transmits it into the TL. The focus, therefore, will be on SLI.

Structural causes refer to cross-linguistic differences in language structure, which consist of word order, information density, abstract vs. concrete diction and hypotaxis vs. parataxis of language.

A purely structural analysis will not suffice to account for SLI, which also results from non-structural causes. Non-structural causes refer to the differences other than language structure, which is analyzed from the cognitive and cultural perspectives respectively.

\section{Consequences of SLI on interpretation}

Owing to the structural and non-structural differences between Chinese and English, SLI in C-E interpretation will have consequences on both the content and form of the interpretation product.

Form is the carrier of content or information in communication process. Any influence of SLI on form will to some extent affect the conveyance of content. The influence of SLI on verbal forms will result in the deterioration of linguistic acceptability while that on non-verbal forms will impair the interpreter's delivery.

While positive transfer will to some extent facilitate language acquisition and use, language interference will produce negative influence, which may result in: underproduction, overproduction, production errors and misinterpretation.

Overproduction is sometimes simply a consequence of underproduction (Terrence, 2001). Owing to cross-linguistic contact, the non-native language is acquired incompletely and some of the linguistic knowledge of the language is neglected, which leads indirectly to the overproduction of structures and expressions transferred from the native language.

The second language learners' existing knowledge about native language and culture sometimes influences his/her perception of the target language. Different word order patterns or cultural assumptions may be the causes of misinterpretation. A typical example is All the books in the library are not open to readers outside the university. It is not unusual for Chinese students to interpret it into the equivalence of "none of the books in the library are open to..." While the exact meaning is that "some books are open and some are not".

\section{Summary}

Interpretation is a highly demanding job that imposes great temporal pressure upon and requires high processing capacity of the interpreter. As a bilingual, the interpreter is to some extent susceptible to language transfer especially language interference between his first and second languages (Tao, 2010). Although a qualified interpreter is expected to possess a high level of proficiency, the impact of SLI still exists. Meanwhile language specificity and the drastic contrast between Chinese and English further precipitate SLI in C-E interpretation. In a word, the working process and features of interpretation and language transfer on the part of the interpreter both contribute to SLI in interpretation.

\section{EXEMPLIFICATIONS OF SLI}

In order to test the structural and non-structural causes that lead to SLI and the effects of SLI on interpretation products, some source materials are quoted and analyzed in this chapter.

\section{A. SLI in Interpreting two Session Source Materials}

The following is the lecture materials when premier Wen Jiabao answered the journalists during the Two Session/Meetings in 2008, proving the influence of SLI.

(1) 五年已经过去了, 行事见于当时, 是非公于后世。

Five years has passed, what one does now will be fairly judged by history.

In the above case, “行事见于当时，是非公于后世” is interpreted in a delicate way, with the full use of the SL 
structure. e.g.: “当时” and “后世” are according interpreted into “now” and “by history”, located in the end. “what one does” is “行事”, while “will be fairly judged” is “公于”. Both are cases for SL imitation. But it's not confined to the SL by word-word interpretation. e.g.: “见于” and “是非”. The interpretation is not only a brief conveyance of Premier's lecture, but also efficient.

(2)一位领导者应该把眼睛盯住前方。

As a leader, his eyes should be on the way ahead.

(3)我们必须在这两者之间走出一条光明的路子。

That's why we needs to blaze a trail in between that will ensure a bright future.

In case (2), premier Wen says that one's eyes should be on the way ahead, similar to "unit to look ahead", which is the habitual expression in Chinese and actually means that the leader should pay more attachments to the future circumstance. While in English, it is said "keep your eyes on the stars" However, the interpreter chooses to succumb to the SL. Instead of interpreting it into "a leader should keep his eyes on the stars", the interpreter acts according to the original text, which is within the tolerating limit of English, keeping both the form and taste of the original text which is a reflection of the SLI.

Case (3) is put forward when the premier introduces that the Chinese economy is facing up with 2 major issues: the over-fast increasing of the price and the pressure of inflation "to blaze a trail in between that will ensure a bright future" and “在这两者之间走出一条光明的路子” is not a change of the metaphor, but process in accordance with the image in it. Whereas in interpreting under the SLI, the interpreter may meet with some extra questions.

(4) 经济体制改革和政治体制改革要有新的突破, 这就必须要解放思想, 解放思想, 这就必须要有勇气、决 心和献身精神, 解放思想和改革创新, 如果前者是因的话, 那么后者就是果。

We need to make new breakthroughs in advancing the reform of the political system and economic system. To attain this goal we need to free our mind. And to free our mind we need to have the courage, resolve and the spirit of dedication. And when we talk about the freeing of our mind and reform and innovation, I believe that the former, the freeing of our mind is the cause and the latter reform and innovation is the effect.

In the above case, “解放思想” is interpreted as “the freeing of our mind”, “改革创新” into “reform and innovation”. But the plus of “和”, namely “and", after them may give the audience a misunderstanding that "freeing of our mind", "reform" and "innovation" are three separate parts. Then the appearance of "the former" and "the latter" will make the audience unclear of how to divide the above into 2 groups. Under such circumstance, if the interpreter still interprets without any change, then misunderstanding is unavoidable. Thus the interpreter repeats "the freeing of our mind" after "the former", and "the latter" to inform the reader of the parallel relationship among the above three noun-phrases.

Whereas, in some situations, if one just restores the content literally, though being faithful and smooth, he can't be a successful interpreter. What's worse, mistake may be made during the process. e.g.:

(5)特别是尽快实现三通。

We want to resume the three direct links between the two sides as quickly as possible. If the interpreter use "realize" or "start" without any modification, misunderstanding will come into being, since there had been the three direct links ago and they are interrupted anyway.

\section{B. SLI in Interpreting Poems in Journalist Reception Meeting}

Further explanation is made by comparing several poems quoted by Premier Wen Jiabao. “行百里者半九十” means it's only a half of the 100 mile's journey if you walk 90 miles, signifying that the nearer you approach success, the harder it becomes, the more serious you need to be. While by comparing with the SL, we may find that the interpreter didn't explore its deep meaning. Instead, he organized his wording in accordance with the literal meaning, interpreting all the “者、半、百里” and achieving the aim of communication, which can be a certification of the full use of SL effect. Later, the famous Chinese diplomatic interpreter Guo Jiading provided the more appropriate interpretation: For a journey of 100 miles, 90 miles is only halfway. Senior Guo's interpretation is given under the full consideration of SL and it's impossible for the junior interpreter to do so in meetings.

Premier Wen also took another poem: “亦余心之所向兮, 虽九死其犹未悔”, means that I should stick up to my ambition at any expense. The interpretation was: For the ideal that I hold the dear to my heart, I'd not regret a thousand times to die. Similarly, the literal consistence is achieved since the interpretation was in consistence with the SL, especially the former part of the sentence. It's acceptable to replace the figure “九” with “a thousand times”, which are the same in fact, for in Chinese “九” has the meaning of "a great many". Later, Senior Guo said that the above interpretation had no problem in meaning conveyance, but lacked briefness. He suggested improving it like this: In pursuit of one's heart's desire, one thousand deaths would bring no regret. Senior Guo's interpretation is extremely correct, but the former interpretation obviously took advantage of the SL effect, reflected in structure:

“不畏浮云遮望眼，只缘身在最高层”.

The interpreter: We have no fear of the clouds that may block our sight as we are already at the top of the height.

Senior Guo: We have no fear of the dark clouds blocking our view, because we are atop the mountain.

There is no big difference between the two versions of the interpretation, except that the former is a long sentence, 
while the latter uses an adverbial clause. Both choose not to extend the connotation, but to express the literal meaning, which is just the SLI Premier Wen quoted this poem to show that the negotiators should stand higher and look further, despite the interference of the outside.

Drawn from the above instances, SLI, following up SL is a passive interpreting mode due to the instance of interpretation on the surface. However it's the result of the active use of SL effect, a moderation to adapt to the regular, improving the efficiency of interpretation greatly. So the SLI is of great importance in interpretation.

\section{Summary}

By comparing, we can draw the conclusion that when the source speech was removed of SLI, more information was conveyed in the target language output and thus the overall quality and communication function of interpretation was improved. Thus it is plausible that structural, cognitive and cultural SLI is a source of deterioration in the performance of the interpreter.

There are also some evidences showing how different way of categorization and thus different semantic categories affected the output in interpretation. One may interpret “In one hand ...in the other..." into “... 一方面...另一方面..." while it actually means "in the hand of the Statue of Liberty". Another example is the misinterpretation of "attend the games” into “参加比赛” while in Chinese “参加比赛” may connote the meaning of "to take part in the game” (Cai \& Zeng, 2004, p.49-54).

Since clear conveyance of information is an essential quality of successful interpretation, thus the assessment of interpretation focuses on the particular point of information correctly rendered in the target language, which does not necessarily mean that the message is conveyed in a clear and appropriate way. Moreover, other factors such as grammatical errors, unfinished sentences, hesitant delivery, etc., can greatly reduce the quality perceived by the audience and in some cases prevent accurate comprehension of the interpretation. To measure the overall quality of interpretation as affected by SLI, other methods should be employed.

\section{SOLUTIONS TO SLI IN INTERPRETATION}

As causes of SLI are classified and analyzed and its consequences tested in the source materials quoted above, it is necessary to explore for possible strategies to tackle SLI. Professional interpreters employ strategies in real time interpretation, which help fulfill the stressing task. Some general approaches and specific strategies are proposed to minimize SLI in C-E interpretation. The general approaches are basic principles to be carried out throughout interpretation process while the application of specific strategies is subject to the interpretation context and the interpreter's choice.

\section{A. General Approaches}

There are three general approaches proposed here, namely, awareness of language difference, general correspondence, and interpretive approach. Appropriate adoption of these approaches will facilitate reduction of SLI in that: awareness of language difference is rudimental in the interpreter's cognition of interpretation reality; general correspondence and interpretive approach help the interpreter to treat the source speech as a meaning-transmitting whole instead of discrete segments.

\section{Awareness of language difference}

As analyzed before, there is a great contrast between the language structures of Chinese and English in terms of word order, information density, and abstract vs. concrete diction and hypotactic vs. paratactic structure. Awareness of the language difference between Chinese and English is something fundamental for the interpreter. e.g.: "as cool as a cucumber”, “班门弄斧.” In Chinese there is not any connection between “cool” and “cucumber” while non-Chinese audience may not have the concept of “班门弄斧”. Since Chinese and English are different, in interpreting from either language to the other, relevant strategies and tactics are indispensable to overcome the difference. Therefore awareness of the language difference prevents the interpreter from rigid trans-coding and enables him/her to master the essence of interpretation.

\section{General correspondence}

There are five levels of correspondence of semantic categories between SL and TL: basic correspondence, relative correspondence, categorized correspondence, functional correspondence and zero correspondence (Liu, 2004). Basic correspondence means the agreement in concept, form and function; relative correspondence refers to basic agreement in concept with difference in form, e.g. synonymy; and categorized correspondence refers to the use of a category name to correspond to its member. The last two should be the main concern when tackling SLI because they are not as easily identified as the former three.

On one hand, the SL interpreter should process the SL segment by segment; on the other hand, he/she should manage the general correspondence of the SL and TL and ensure the integration of the interpreted text. That is one of the difficult points of SL.

\section{Interpretive approach}

From the term interpretation we know that some explanation is involved in the process, since "to interpret" also bears the meaning "to explain". 
To accomplish his/her task, the interpreter needs to comprehend the source speech and reproduce it in the TL. In the above process the interpreter first extracts the meaning from a particular segment, which will be discussed later, then the wording of SL disappears and he/she tries to re-express the meaning in the TL. That is what "interpretive approach" means.

Interpretation is a service intended ultimately for the audience. The aim of the service is to get the meaning of the speaker across to the audience in real time. Therefore the interpreter should also involve some explanation whenever necessary to facilitate the conveyance of meaning other than performing simply literal translating.

\section{B. Specific Strategies}

Strategies play an important role in successful interpretation. Moreover, the role of strategies is not to eliminate all SLI but to minimize it. Some basics about strategies to cope with SLI in interpretation are introduced here.

\section{Linearity}

Linearity refers to general consistence with the basic SL linguistic order in the rendering of the TL. Both Chinese and English have the basic word order of "subject-verb-object", which provides the basis for linearity. In practice, however, there are several points that need to be noted:

First, "general consistence" does not imply word-for-word or phrase-for-phrase or any fixed linear correspondence between the SL and the TL.

Second, "basic SL linguistic order" is not understood in a strict sense. If, apparently, a SL structure is more appropriately rendered in the TL with some adjustment in its linguistic order, then the interpreter should not hesitate to do so, as long as the flow of thought of the speaker is conveyed to the target audience.

Third, linearity should not confine the interpreter in his/her rendering of the TL (Tao, 2010).

Maintaining linearity helps the interpreter to optimize processing capacity management. Linearity also contributes to the fluency and simultaneity of TL output in interpretation. Linearity guarantees a moderate time lag, which allows the interpreter to free himself/herself from the surface structure of the SL text and optimize his/her delivery in the TL. It is up to the interpreter to decide on what scale and to what extent linearity should be applied to achieve optional interpretation products.

\section{Anticipation}

"The interpreter's ability to anticipate is defined on the one hand by his linguistic competence, i.e. his knowledge of syntactic and semantic regularities in the SL and the use of information from previously processed text, and on the other hand by his knowledge of the situation, especially the role of the sender and his typical behavior in that role and situation, and the interpreter's prior knowledge of the subject. Accordingly, there are two types of anticipation: linguistic and extra linguistic anticipation.

Anticipation is applied when a postponed element (e.g. a noun head) in the SL should be rendered much easier in the TL. Waiting for the postponed element before interpreting will cost great effort in terms of short-term memory while proper anticipation alleviates memory load efficiently and facilitates the interpreter's psychological pressure when waiting and accurate anticipation increases his/her confidence for the interpretation task.

\section{Principle of economy}

There are several specific techniques for principle of economy including simplification, omission, abbreviation and approximation, etc.

Simplification refers to rendering the complicated SL structures in a simpler way in the TL. Redundant elements like flowery rhetorical language may be handled with simplification.

Omission of some SL elements is another method. Some SL elements that are not in line with the TL norms may be omitted to maintain the idiomaticness and conciseness of expression.

Abbreviation and approximation of numbers are also commonly applied. Both in English and Chinese, the interpreter can choose to use abbreviation whenever applicable, e.g. GEF (Global Environment Facility), IMF (International Monetary Fund), 发改委 (国家发展和改革委员会), 贸促会 (中国国际贸易促进委员会). Approximation of numbers is an effective way of reducing processing effort in interpretation. e.g.: In 1999, China's agricultural production continued to develop with the output of grain reaching 20839 million tons. Here the number may be interpreted as “2 亿 8 百多万吨”.

By condensing the source speech, the principle of economy reduces the efforts needed for TL production and articulation, leaving more capacity for comprehension and memory, and thus provides a way of coordinated capacity management. Economy of expression is also a remedy for time constraint in interpretation. Moreover, it contributes to information conveyance, instead of impairing it, by removing redundancy and producing the most efficient expression in the TL.

\section{CONCLUSION}

In the thesis the author focuses on the study of SLI in C-E interpretation. SLI and interpretation are clearly defined. Causes of SLI in C-E interpretation consist of structural and non-structural factors. In the analysis of structural factors, the major differences between Chinese and English language structures are word order, information density, abstract vs. concrete diction and hypotaxis vs. parataxis, each with examples and illustrations. Non-structural factors are composed 
of cognitive aspects and cultural aspects. Then is the consequence of SLI on both the content and form of the interpretation product, thus affecting the quality and communicative function of interpretation.

The lecture materials Premier Wen Jiabao answered the journalists during the Two Session/Meetings in 2008 is carried out to provide some evidence that the structural and none-structural factors discussed herein do exert some influence on the information conveyance in interpretation.

It is proposed that the interpreter should be aware of these underlying factors of SLI and select appropriate strategies to minimize SLI in C-E interpretation. Both general approaches and specific strategies should be employed to cope with SLI. Awareness of language difference, general correspondence, interpretive approach are the general guidelines to be adopted by the interpreter consciously or subconsciously. Linearity, anticipation and principle of economy are specific strategies to tackle real time SLI. It should be noted that possible strategies couldn't be exhausted in this thesis. It is subject to the interpreter to apply or develop new strategies based on the general approaches and particular situations.

\section{REFERENCES}

[1] Cai Xiaohong and Zeng Jieyi. (2004). Historical review of interpretation quality evaluation. Chinese Translators journal 3: 49-54.

[2] Daniel,G. (1995). Basic Concepts and Models for Interpreter and Translator Training. Amsterdam/Philadelphia: John Benjamin's Publishing Company.

[3] Liu Biqing. (2004). Theoretical study on translation. Beijing: China's publishing company.

[4] Robin, S. (1993). Simultaneous Interpretation: a Cognitive-Pragmatic Analysis. Amsterdam/Philadelphia: John Benjamins Publishing Company: Amsterdam/Philadelphia.

[5] Taolin. (2010). Source language interference in interpretation. Anhui literature 1: 114.

[6] Terence, O. (2001). Language Transfer. Shanghai: Shanghai Foreign Language Education Press.

Haiyan Gao was born in Linyi, China in 1983. She received her Master degree in English language and Literature from Liaocheng University, China in 2009.

She is currently an instructor in the School of Foreign Languages, Heze University, China. Her research interests include English language and literature, text translation, and English teaching. 